\title{
Involvement of the Autonomic Nervous System in the In Vivo Memory to Glucose of Pancreatic $\beta$ Cell in Rats
}

\author{
Jean-Michel N'Guyen, * Christophe Magnan, * Marie-Claude Laury, * Catherine Thibault, * Jean Leveteau, ${ }^{*}$ Marc Gilbert, * \\ Luc Pénicaud, ${ }^{*}$ and Alain Ktorza* \\ * Laboratoire de Physiopathologie de la Nutrition, CNRS URA 307, Université Paris 7-Denis Diderot, and ${ }^{\ddagger}$ Institut des Neurosciences, \\ Université Paris 6-Pierre et Marie Curie, Paris, France
}

\begin{abstract}
The fact that the potentiating effect of prolonged hyperglycemia on the subsequent insulin secretion is observed in vivo but not in vitro suggests the involvement of extrapancreatic factors in the in vivo memory of pancreatic $\beta$ cells to glucose. We have investigated the possible role of the autonomic nervous system. Rats were made hyperglycemic by a $48-h$ infusion with glucose (HG rats). At the end of glucose infusion as well as $6 \mathrm{~h}$ postinfusion, both parasympathetic and sympathetic nerve activities were profoundly altered: parasympathetic and sympathetic activities, assessed by the firing rate either of the thoracic vagus nerve or the superior cervical ganglion, were dramatically increased and decreased, respectively. Moreover, $6 \mathrm{~h}$ after the end of glucose infusion, insulin secretion in response to a glucose load was dramatically increased in HG rats compared to controls. To determine whether these changes could be responsible for the increased sensitivity of the $\beta$ cell to glucose, insulin release in response to glucose was measured in HG and control rats, either under subdiaphragmatic vagotomy or after administration of the $\alpha_{2 \mathrm{~A}}$-adrenergic agonist oxymetazoline. Both treatments partially abolished the hyperresponsiveness of the $\beta$ cell to glucose in HG rats.

Therefore chronic hyperglycemia brings about changes in the activity of the autonomic nervous system, which in turn are responsible, at least in part, for the generation of enhanced $\beta$ cell responsiveness to glucose in vivo. (J. Clin. Invest. 94:1456-1462.) Key words: glucose infusion • parasympathetic activity $\bullet$ sympathetic activity $\bullet$ insulin secretion - oxymetazoline.
\end{abstract}

\section{Introduction}

It has long been recognized that the magnitude of the insulin secretory response to glucose or nonglucose stimuli is influenced by prior exposure to glucose. For example, a time-dependent potentiation of glucose-induced insulin secretion by a previous short-term stimulation with glucose has been demon-

Address correspondence to A. Ktorza, Laboratoire de Physiopathologie de la Nutrition, CNRS URA 307, Universite Paris 7-Denis Diderot, Tour 23-33, $1^{\circ}$ etage, 2 Place Jussieu, 75251 Paris Cedex 05, France. Received for publication 2 February 1994 and in revised form 30 June 1994.

J. Clin. Invest.

(C) The American Society for Clinical Investigation, Inc. 0021-9738/94/10/1456/07 \$2.00

Volume 94, October 1994, 1456-1462 strated from studies in humans (1), and isolated rats' islets (2) or pancreas (3). The study of the kinetic characteristics of glucose-induced potentiation allowed a better understanding of the biphasic pattern of insulin release (4). Moreover, hyperglycemia induced in nondiabetic humans during several hours by a continuous glucose infusion resulted in an enhanced $\beta$ cell sensitivity to glucose as assessed by an increase in the slope of glucose potentiation of arginine (5), or by the higher amount of insulin secreted during intravenous glucose tolerance tests (6). We have previously shown that in nondiabetic rats submitted to a 48-h hyperglycemic period, in vivo insulin secretion to intravenous glucose was dramatically increased. The potentiating effect of previous hyperglycemia on pancreatic $\beta$ cell responsiveness persisted for a long time after the withdrawal of the first stimulus, since glucose-induced insulin secretion remained higher than in controls until at least $5 \mathrm{~d}$ after the first priming period of glucose (7).

However, when insulin secretion was studied in vitro by the perfused pancreas technique in nondiabetic rats rendered previously hyperglycemic, the priming effect of glucose could never be observed as well in our study (7) as in others $(8,9)$. In some studies, insulin release was even decreased $(10,11)$.

This discrepancy stresses the importance of extrapancreatic factors in the modulation of the long-term effects of high glucose levels on pancreatic islets in vivo and their possible involvement in the memory of $\beta$ cells to glucose. Among these factors, those of neural origin may play a crucial role. The neuronal inputs of the pancreas include the parasympathetic and sympathetic systems whose activation results in the stimulation or the inhibition of insulin secretion, respectively (12). On one hand it has been recently demonstrated that cholinergic agonists prime the $\beta$ cell to glucose stimulation (13), and on the other, decreased sympathetic activity is involved in the high pancreatic responsiveness to glucose in hyperinsulinemic rats $(14,15)$.

We hypothesized that prolonged and elevated hyperglycemia in rats could lead to high parasympathetic and low sympathetic tone that will persist after the priming period with glucose. Consequently, this would contribute to the high in vivo insulin secretory response to a subsequent stimulation with glucose.

To test this hypothesis, we have infused nondiabetic rats with glucose for $48 \mathrm{~h}$ and thereafter we studied the firing rate of the vagus nerve and the superior cervical ganglion to assess the overall parasympathetic and sympathetic activities respectively, and the in vivo insulin secretory response to a glucose load, either under subdiaphragmatic vagotomy, or after a treatment with an $\alpha_{2 \mathrm{~A}}$ adrenoreceptor agonist, oxymetazoline.

\section{Methods}

Animals. 3-mo-old female Wistar rats (220-250 g) having free access to water and standard laboratory chow pellets (UAR 113; Usine d'Ali- 
mentation Rationnelle, Villemoisson sur Orge, France) were used. They were maintained at a constant temperature $\left(23^{\circ} \mathrm{C}\right)$ in animal quarters with a fixed $(12 \mathrm{~h})$ artificial light cycle. The technique for long-term infusion in unrestrained rats was used as described previously $(7,16)$. The infusion period started on day 2 after surgery and lasted $2 \mathrm{~d}$. Hypertonic (30\% wt/vol) glucose (Chaix \& Du Marais, Paris, France) was infused at the initial infusion rate of $50 \mu 1 / \mathrm{min}$ to produce hyperglycemia of 20-25 mmol/liter. The initial infusion rate was slightly modulated throughout the infusion period to maintain glycemia in the desired range. When glycemia was not maintained in the limits mentioned above, the experiment was discontinued. Control rats were infused with a glucose-free solution.

Blood samples. Plasma glucose and insulin concentrations were measured on arteriovenous blood collected from the tail vessels three times daily in glucose-infused (HG) ${ }^{1}$ rats. Because previous studies have shown that in control (C) rats these parameters remained very stable throughout the infusion period (7), these parameters were measured only once daily in this group. At the end of the infusion period, plasma glucose and insulin concentrations were measured in both groups of rats every hour until time $2 \mathrm{~h}$ postinfusion and every $2 \mathrm{~h}$ until time $6 \mathrm{~h}$ after the infusion was discontinued.

Sympathetic and parasympathetic firing rate recording. Firing rate activities were recorded at the end of glucose infusion period and $6 \mathrm{~h}$ postinfusion. Sympathetic activity was recorded at the level of the superior cervical ganglion and, for parasympathetic activity recording, the thoracic branch of the vagus nerve, along the carotid, was used. Different rats were used for recording either activity.

For sympathetic activity recording, the method was the following one: briefly, rats were anesthetized $(48 \mathrm{mg} / \mathrm{kg}$ of body wt i.p. with pentobarbital sodique; Sanofi, Libourne, France) and after a latency period of $20 \mathrm{~min}$, the carotid was exposed. The sympathetic nerve filament, which is close to the artery, was dissected free of underlying tissues on a distance of about $1 \mathrm{~cm}$ until the superior cervical ganglion. The nerve was then covered with paraffin oil to prevent dehydration and carefully placed on a pair of recording silver wire electrodes $(0.6$ $\mathrm{mm}$ diameter). The nerve impulse was filtered $(1-80 \mathrm{kHz})$ and amplified $\left(10^{4}\right)$ with an alternative current amplifier (time-constant: $0.2 \mathrm{~s}$ ) and then summated with an integrator (time-constant: $0.5 \mathrm{~s}$ ). The signal was simultaneously displayed on an oscilloscope and a pen recorder and stored on a magnetic tape for further analysis.

A very similar experimental design was used for parasympathetic activity recording. After exposure of the carotid, the thoracic branch of the vagus nerve, which is very close to the artery, was carefully separated from surrounding tissues. The follow-up of the procedure was identical to that described for sympathetic nerve activity recording.

In vivo insulin secretion tests in intact, untreated rats. All tests were performed $6 \mathrm{~h}$ after the infusion was discontinued. Insulin secretion was investigated in $\mathrm{C}$ and $\mathrm{HG}$ rats in the following way: rats were in the postabsorptive state under ketamine hydrochloride anesthesia $(95 \mathrm{mg} /$ kg i.p.; Imalgène, Mérieux, France). A single injection of glucose (0.5 $\mathrm{mg} / \mathrm{kg}$ of body wt) was administered via the saphenous vein. Blood samples were collected sequentially before and $5,10,15,20,30$, and $60 \mathrm{~min}$ after the injection of glucose. They were then centrifuged and the plasma was separated. Plasma glucose concentration was immediately determined on a 10- $\mu \mathrm{l}$ aliquot, and the remaining plasma was kept at $-20^{\circ} \mathrm{C}$ until radioimmunoassay of insulin.

Insulin secretion after suppression of vagal activity. In a series of experiments, HG and C rats were submitted to a bilateral vagotomy 20 $\mathrm{min}$ before in vivo insulin secretion was investigated. Briefly, rats under ketamine hydrochloride anesthesia ( $95 \mathrm{mg} / \mathrm{kg}$ i.p.) were laparotomized,

1. Abbreviations used in this paper: $\mathrm{C}$, control rats; $\mathrm{C}_{\mathrm{oxy}}$, oxymetazolineinjected control rats; $\mathrm{C}_{\mathrm{v}}$, vagotomized control rats; $\mathrm{HG}$, glucose-infused rats; $\mathrm{HG}_{\mathrm{oxy}}$, oxymetazoline-injected glucose-infused rats; $\mathrm{HG}_{\mathrm{v}}$, vagotomized glucose-infused rats; IRI, immunoreactive insulin.
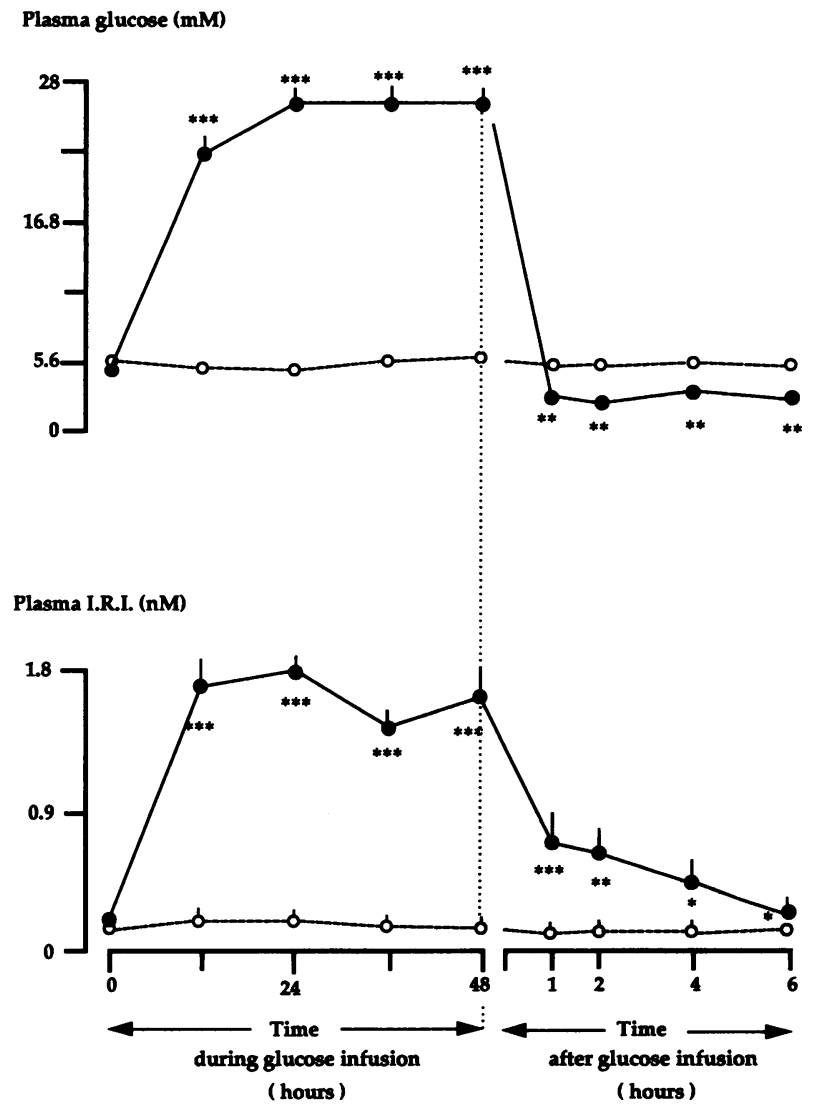

Figure 1. Plasma glucose and IRI concentrations in HG $(\bullet)$ rats during and after the end of the infusion and in $\mathrm{C}$ rats $(0)$ during the same period. Values are means \pm SEM of 37 and 52 cases for $C$ and HG rats, respectively. ${ }^{* * P}<0.01, * * * P<0.001$, significantly different from $\mathrm{C}$ rats.

and the stomach and the spleen were lifted to the right and the left, respectively. The subdiaphragmatic anterior and posterior trunks of the vagus nerves were exposed approximately halfway between the diaphragm and the gastric cardia. With the aid of a retractor system which maintained the patency of the midline incision gaping, the surgical transection of the vagal trunks was carried out with curved forceps. The stomach and the spleen were then returned to their normal position and the abdominal wall was closed. Glucose-induced insulin secretion was investigated under the same conditions as mentioned above.

Insulin secretion in the presence of the $\alpha_{2 A}$-adrenergic agonist, oxymetazoline. In another series of experiments insulin secretion was studied in HG and C rats after the injection of the $\alpha_{2 \mathrm{~A}}$-adrenergic agonist, oxymetazoline. Briefly, rats were anesthetized $(95 \mathrm{mg} / \mathrm{kg}$ i.p.; Imalgène) and a catheter was inserted into the right carotid artery which was connected to a pressure transducer (Elecdan Epox-Alim, Lavelanet, France) to measure arterial pressure. Arterial pressure was recorded in the basal state and throughout the rest of the experiment. After a recovery period of about $20 \mathrm{~min}$, oxymetazoline hydrochloride (Sigma Chemical Co., St. Louis, MO) was injected intraperitoneally at the dose of $0.3 \mathrm{pmol} / \mathrm{kg}$ body wt, $5 \mathrm{~min}$ before the study of glucose-induced insulin secretion.

Analytical methods. Plasma glucose was determined by means of a glucose analyzer (Beckman Instruments, Inc., Palo Alto, CA). Plasma immunoreactive insulin (IRI) concentration was determined using a radioimmunoassay kit (Commissariat à l' Energie Atomique, Gif-surYvette, France). The lower limit of the assay was $2.5 \mu \mathrm{U} / \mathrm{ml}$ with a coefficient of variation within and between assay of $6 \%$. 
Table I. Parasympathetic and Sympathetic Activities in $C$ and $H G$ Rats at the End of Glucose Infusion and $6 \mathrm{~h}$ after the End of Glucose Infusion

\begin{tabular}{llcc}
\hline & & \multicolumn{2}{c}{ HG rats } \\
\cline { 3 - 4 } & \multicolumn{1}{c}{$\mathrm{C}$ rats } & $\begin{array}{c}\text { At the end of } \\
\text { glucose infusion }\end{array}$ & $\begin{array}{c}6 \mathrm{~h} \\
\text { postinfusion }\end{array}$ \\
\hline $\begin{array}{c}\text { Parasympathetic activity } \\
\text { (spikes/s) }\end{array}$ & $\begin{array}{l}2.20 \pm 0.30 \\
(n=5)\end{array}$ & $\begin{array}{c}8.50 \pm 0.50^{*} \\
(n=6)\end{array}$ & $\begin{array}{c}9.80 \pm 1.30^{*} \\
(n=5)\end{array}$ \\
$\begin{array}{c}\text { Sympathetic activity } \\
\text { (spikes/s) }\end{array}$ & $\begin{array}{l}2.80 \pm 0.30 \\
(n=5)\end{array}$ & $\begin{array}{c}0.40 \pm 0.04^{*} \\
(n=6)\end{array}$ & $\begin{array}{c}0.48 \pm 0.08^{*} \\
(n=5)\end{array}$ \\
\hline
\end{tabular}

Values are means \pm SEM. $n$, number of experiments. ${ }^{*} P<0.001$, HG vs. $\mathrm{C}$ rats. Parasympathetic and sympathetic activities were recorded from vagus nerve and superior cervical ganglion, respectively.

Calculations. Insulin response to glucose was calculated as the insulinogenic index $(\Delta \mathrm{IRI} / \Delta \mathrm{G})$ which represented the ratio of the incremental plasma insulin values integrated over a period of $60 \mathrm{~min}$ after the injection of glucose ( $\Delta \mathrm{IRI})$ and the corresponding increase in glucose concentration $(\Delta G)$. Results are expressed as mean \pm SEM.

The significance of the differences between means was evaluated by a one- or two-way ANOVA.

\section{Results}

Plasma glucose and insulin concentrations during and after glucose infusion. Sustained and steady hyperglycemia was produced in rats throughout the period of glucose infusion (25 2.4 $\mathrm{mM}$ in HG rats, $n=52$ vs. $5.6 \pm 0.1 \mathrm{mM}$ in C rats, $n=37$ ). Hyperglycemia resulted in a dramatic hyperinsulinemia during the infusion period in HG rats. The mean plasma insulin was about 10-fold higher in HG than in $\mathrm{C}$ rats $(1.60 \pm 0.16 \mathrm{nM}, n$ $=52$ vs. $0.16 \pm 0.03 \mathrm{nM}, n=37, P<0.001$; Fig. 1 ).

In HG rats, plasma glucose concentration decreased rapidly to basal values as early as $1 \mathrm{~h}$ after glucose infusion was termi- nated. It continued to decline afterwards so that $6 \mathrm{~h}$ after the end of the infusion, it was significantly lower than in $\mathrm{C}$ rats (3.6 $\pm 0.3 \mathrm{mM}$ in HG rats, $n=52$ vs. $5.7 \pm 0.2 \mathrm{mM}$ in C rats, $n$ $=37, P<0.01$ ). Concomitantly, plasma insulin concentration also decreased and was similar in HG $(0.21 \pm 0.01 \mathrm{nM}, n=52)$ and $C$ rats $(0.16 \pm 0.02 \mathrm{nM}, n=37)$ at $6 \mathrm{~h}$ postinfusion.

Parasympathetic and sympathetic nerve activities. At the end of glucose infusion period as well as $6 \mathrm{~h}$ postinfusion, both parasympathetic and sympathetic nerve activities were profoundly altered in HG rats. The firing rate of the vagus nerve was dramatically increased compared with $\mathrm{C}$ rats, as reflected by spikes frequency (Table I) and integrated activity (Fig. 2 $A)$. By contrast, superior cervical ganglion firing rate was largely lower in HG than in C rats (Table I; see also Fig. 2 B).

Insulin secretion in response to intravenous glucose in intact, untreated rats. The time-course of plasma glucose concentration before and after the glucose load is depicted in Fig. 3 and as the $\Delta G$ (Table II). In all cases, plasma glucose concentrations increased to a much lesser extent in HG than in $\mathrm{C}$ rats but the $\Delta$ Gs were roughly similar in both groups (Table II).

At time $0 \mathrm{~min}$ (before glucose injection), plasma insulin concentration was slightly but not significantly higher in HG than in $\mathrm{C}$ rats. It increased markedly after glucose injection in both groups. In HG rats it was much more elevated at every point-time of the test than in $\mathrm{C}$ rats (Fig. 4). This situation was reflected in the $\Delta$ IRI as well as in the insulinogenic index $(\Delta \mathrm{IRI} / \Delta \mathrm{G})$ values which were three- and fourfold greater in HG than in C rats, respectively (Table II).

Effect of vagotomy on insulin secretion in response to intravenous glucose. The $\Delta G$ was increased to the same extent in HG $\left(\mathrm{HG}_{\mathrm{v}}\right)$ and $\mathrm{C}\left(\mathrm{C}_{\mathrm{v}}\right)$ vagotomized rats, as compared to intact rats (Table II). Insulin secretion in response to glucose was not significantly modified by vagotomy in $C$ rats (Fig. 4 , and Table II). By contrast, it was markedly reduced in $\mathbf{H G}_{\mathbf{v}}$ rats compared to intact HG rats; plasma insulin was much lower at point-time 5, 10, and 15 min (Fig. 4) and the $\Delta I$ was significantly decreased, while no significant difference was observed between
(A)

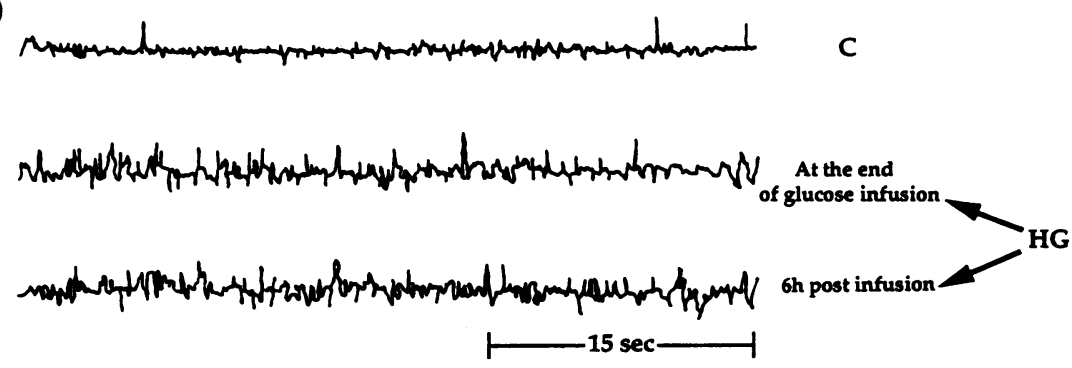

(B)
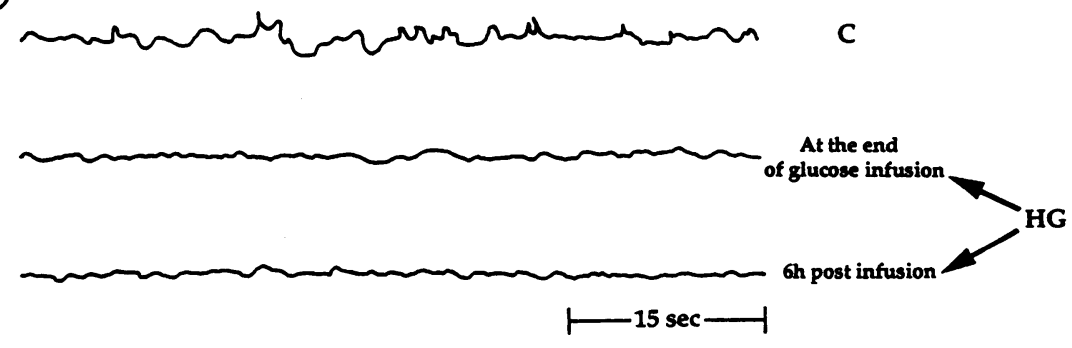

Figure 2. Fragments of illustrative recordings of parasympathetic and sympathetic nerve activity from $\mathrm{C}$ and $\mathrm{HG}$ rats at the end of glucose infusion and $6 \mathrm{~h}$ postinfusion. Parasympathetic $(A)$ and sympathetic $(B)$ activities are displayed as mean voltage. Each peak represents spontaneous spikes of parasympathetic and sympathetic discharges. Each trace was obtained from different rats. 


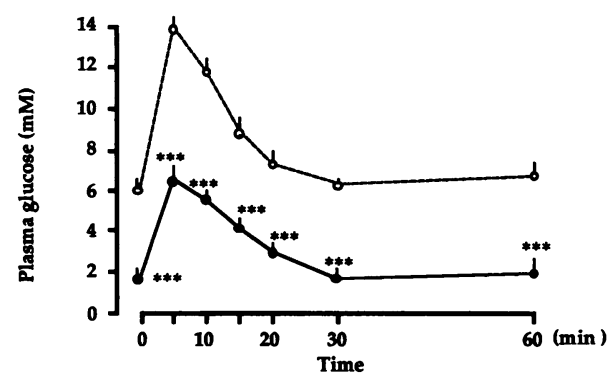

B

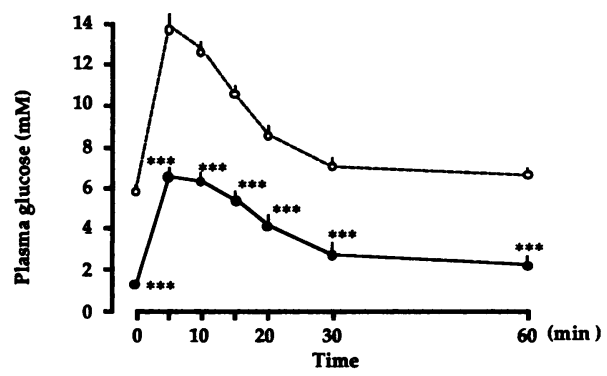

C

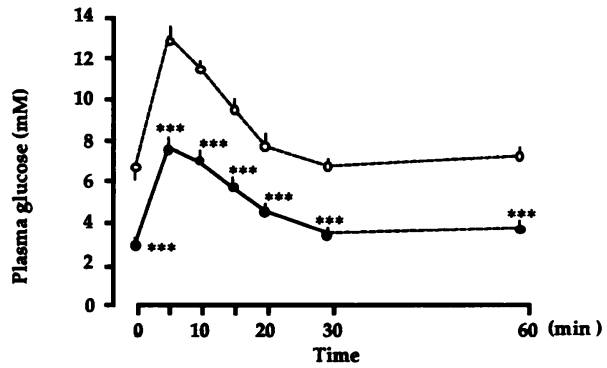

Figure 3. Variation of plasma glucose concentrations in response to glucose loading in $C(O)$ and $H G(\bullet)$ rats, $6 \mathrm{~h}$ postinfusion. The tests were performed either in intact rats $(A)$, after subdiaphragmatic vagotomy $(B)$, or under oxymetazoline treatment $(C) .{ }^{* * *} P<0.001$ significant differences between $\mathrm{HG}$ and $\mathrm{C}$ rats.

$\mathrm{C}_{\mathrm{v}}$ and $\mathrm{C}$ rats. This situation was reflected in the insulinogenic index as well: the $\Delta \mathrm{IRI} / \Delta \mathrm{G}$ was significantly lowered in $\mathrm{HG}_{\mathrm{v}}$ rats compared to HG rats (Table II). Consequently, the difference between control and HG rats was attenuated by vagotomy; e.g., the $\Delta \mathrm{IRI} / \Delta \mathrm{G}$ of $\mathrm{HGv}$ rats was not significantly different from that of control intact rats (Table II).

Effect of the $\alpha_{2 A}$ adrenergic agonist oxymetazoline on insulin secretion in response to intravenous glucose. In both groups, the $\Delta \mathrm{G}$ was not noticeably modified by oxymetazoline treatment. As indicated by the time-course of the plasma insulin during the test, oxymetazoline treatment induced different effects on insulin secretion in HG and $\mathrm{C}$ rats. Insulin release was only very slightly modified in oxymetazoline-injected $\mathrm{C}$ rats $\left(\mathrm{C}_{\mathrm{oxy}}\right)$ (Fig. 4 and Table II). By contrast, oxymetazoline treatment largely affected insulin secretion in the $\mathrm{HG}$ group $\left(\mathrm{HG}_{\mathrm{oxy}}\right)$ : at each point-time plasma IRI increased less than in untreated HG rats (Fig. 4). Consequently, the $\Delta I R I$ and, to a greater degree, the $\Delta \mathrm{IRI} / \Delta \mathrm{G}$ were significantly decreased in $\mathrm{HG}_{\text {oxy }}$ rats compared to untreated HG rats. Moreover, the difference with untreated control rats was almost abolished (Table II).
Table II. $\Delta G, \Delta I R I$, and $\Delta I R I / \Delta G$ in Response to Glucose Loading in $C$ and HG Rats under Vagotomy or Oxymetazoline Injection

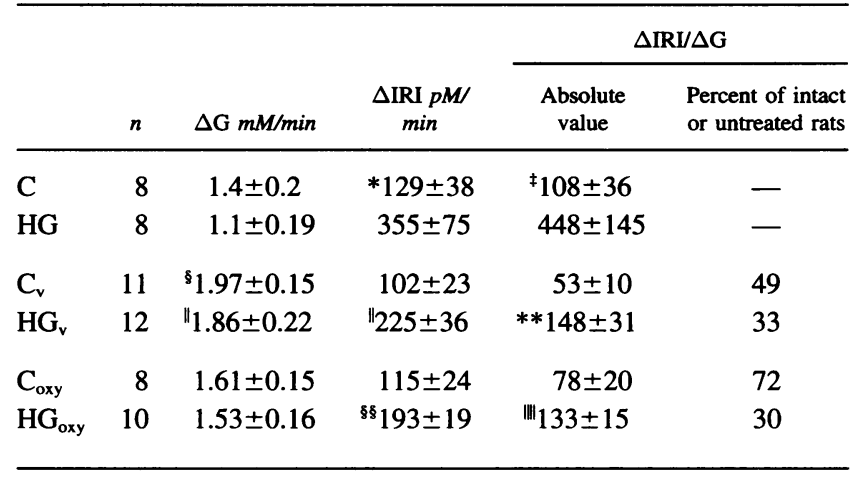

Values are means \pm SEM. $n$, number of experiments. $\Delta G$ and $\Delta$ IRI represent incremental plasma glucose and insulin concentration integrated over a period of $60 \mathrm{~min}$ of test. $\Delta \mathrm{IRI} \Delta \mathrm{G}$, insulinogenic index. ${ }^{*} P<0.01,{ }^{\ddagger} P<0.001$, HG rats vs. control rats. ${ }^{\S} P<0.05, \mathrm{C}_{\mathrm{v}}$ rats vs. C rats. " $P<0.05, \quad * * P<0.001, \mathrm{HG}_{\mathrm{v}}$ rats vs. HG rats. ${ }^{88} P$ $<0.01,{ }^{\text {III }} P<0.001, \mathrm{HG}_{\text {oxy }}$ rats vs. HG rats.

\section{Discussion}

The dramatic increase in plasma insulin concentration consecutive to a 48-h glucose infusion, followed by a return to almost normal values $6 \mathrm{~h}$ after the infusion was terminated, is in accordance with our previous observations $(7,17)$. The persistence of high plasma insulin concentrations over $4 \mathrm{~h}$ after the end of glucose infusion, despite low plasma glucose levels, is of special interest. Provided that this situation could not be ascribed to a decreased insulin degradation and/or an increased peripheral insulin action, it suggests an enhanced sensitivity of pancreatic $\beta$ cells to glucose in vivo. This hypersensitivity is confirmed by the subsequent high insulin response to a slight increase in plasma glucose level after glucose loading in HG rats (Fig. 4). Therefore the high potentiating effect of 48-h hyperglycemia on islet activity in normal rats seems to be largely related to islet hypersensitization. This is in agreement with previous studies showing that long-term exposure to high glucose concentrations lower the threshold of insulin release induced by glucose (1721 ). These changes may be due, at least in part, to increased glucose transporter GLUT-2 affinity and glucokinase activity resulting in increased glucose utilization by the $\beta$ cell (22).

As indicated by the firing rates from the superior cervical ganglion and from the thoracic vagus nerve recorded at the end of the glucose infusion period, both sympathetic and parasympathetic activities were greatly altered by glucose infusion.

Previous studies demonstrated that acute changes in blood glucose concentration may modify parasympathetic nerve activity in several species. Niijima especially reported that intravenous administration of glucose increased the discharge rate in the hepatic branch of the vagus nerve in rabbits (23) and guinea pigs (24), and in both the hepatic and pancreatic branches of the vagus nerves in rats (25). In the latter experiments, the firing rate was closely related to blood glucose over a wide range of concentrations, between 0.6 and $4.5 \mathrm{~g} /$ liter (25). Our findings match these observations. Because the alterations reported in the present study are more pronounced than in studies 
where plasma glucose concentration was acutely and transiently increased, it can be postulated that the increase in parasympathetic nerve activity may be strengthened by the duration and intensity of the glucose stimulus.

The relationships between glucose and insulin concentrations and sympathetic nervous system activity are rather complex. Sympathetic activity is stimulated by carbohydrate feeding, especially glucose and fructose in humans (26) and rats (27). This effect is specific for carbohydrates, because it can be observed in the absence of increase in total caloric intake and cannot be reproduced by artificial sweeteners (28). Conversely, fasting (29) and/or hypoglycemia $(30,31)$ suppress sympathetic activity. However, recent evidence indicates that this relationship is mediated by diet-induced variations in plasma insulin rather than glucose. In rats made diabetic by streptozotocin, which are hyperglycemic and hypoinsulinemic, sympathetic nervous system activity is considerably reduced (32), whereas insulin injection into rats, along with the administration of glucose to maintain euglycemia, stimulates sympathetic nerve activity (32). The same conclusions can be drawn from observations made in humans. Hyperinsulinemia associated either with hypoglycemia (33) or with euglycemia (34) increased skin nerve and muscle nerve sympathetic activities, respectively. Furthermore, Vollenweider et al. (35), performing simultaneous microneurographic recordings and caloric determinations of carbohydrate oxidation rate, showed that hyperinsulinemia per se, and not insulin-induced stimulation of carbohydrate metabolism, was responsible for enhanced sympathetic activity in subjects submitted to insulin/glucose infusions. In fact, according to the experiments performed by Niijima in the rabbit, glucose itself suppresses sympathetic activity. Injection of a $10 \%$ glucose solution, but not of mannose or of $0.9 \% \mathrm{NaCl}$, into the carotid artery or the general circulation decreases the discharge rate of the splanchnic nerve, while hypoglycemia increases it $(23,36,37)$. Our finding of a sharp decrease in the firing rates from the superior cervical ganglion in rats previously submitted to elevated and prolonged hyperglycemia are consistent with these data and support the view of a suppressive effect of a long-term elevation of blood glucose concentration on sympathetic nervous system activity. Our data can also be connected with the recent demonstration of a decreased catecholamine secretion from the adrenals of BB rats which are chronically and severely hyperglycemic (38).

The significant alteration in both sympathetic and parasympathetic nerve activities, consecutive to hyperglycemia, that we observe may be of clinical relevance. Autonomic neuropathy, one of the main complications of diabetes, is involved, at least for a large part, in defective counterregulation and unawareness of hypoglycemia, two interdependent major problems for patients with insulin-dependent diabetes $(39,40)$. Our experimental model seems to be suitable for studying the possible deleterious effects of isolated hyperglycemia on autonomic nervous system activity.

It is noteworthy that parasympathetic and sympathetic nerve activities remained very high and very low, respectively, for several hours after the end of the exposure to glucose, even though plasma glucose level was clearly lower than normal and insulin concentration was not significantly different from that of controls. To our knowledge, this is the first demonstration of a persisting effect of previous hyperglycemia on autonomic
$\mathbf{A}$

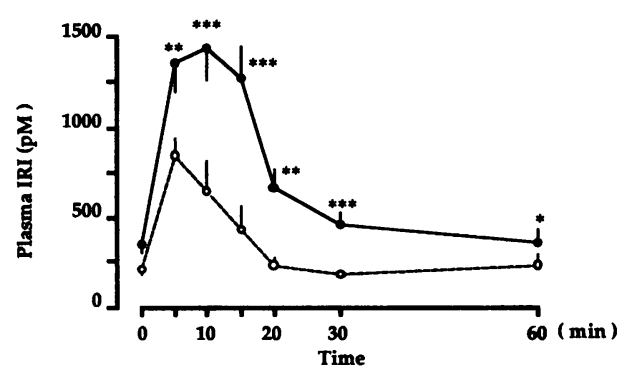

B

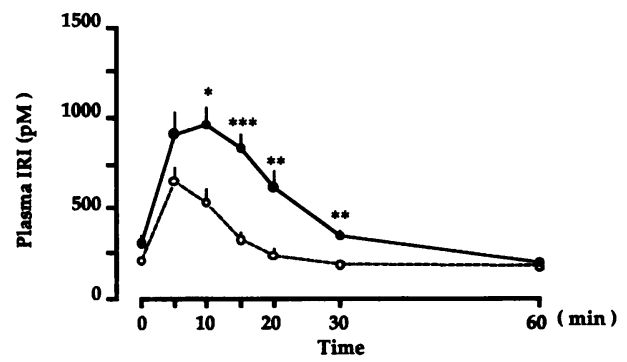

C

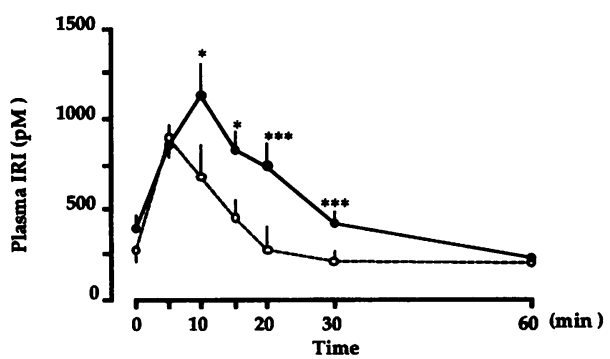

Figure 4. Variation of IRI concentrations in response to glucose loading in $\mathrm{C}(O)$ and $\mathrm{HG}(\bullet)$ rats, $6 \mathrm{~h}$ postinfusion. The tests were performed either in intact rats $(A)$, after subdiaphragmatic vagotomy $(B)$, or under oxymetazoline treatment $(C) .{ }^{*} P<0.05, * * P<0.01, * * * P<0.001$ significant differences between $\mathrm{HG}$ and $\mathrm{C}$ rats.

nervous system activity in nondiabetic rats even after the withdrawal of the stimulus.

It is also significant that rats submitted to glucose infusion were not only hyperglycemic but also highly hyperinsulinemic. The decrease in sympathetic and the increase in parasympathetic activities are, as discussed above, a consequence of hyperglycemia and not of hyperinsulinemia, which has opposite effects on these activities. This suggests that, when hyperglycemia and hyperinsulinemia are present concomitantly, the effects of glucose on the autonomic nervous system activity prevail over those of insulin.

The insulin secretory response to glucose in C and HG rats submitted either to vagotomy or to oxymetazoline treatment, strongly suggests that the overall high parasympathetic and low sympathetic tones that we observed in HG rats contribute to the oversecretion of insulin. The decrease in insulin release in HG rats, under both conditions is actually due to the treatments themselves and not to alterations in the glycemic profiles after glucose loading, which were very similar in intact and $\mathbf{H G}_{\mathbf{v}}$ or $\mathrm{HG}_{\text {oxy }}$ rats (Fig. 3 ).

The involvement of the parasympathetic nervous system in 
the pancreatic $\beta$ cell hyperresponsiveness to glucose is evidenced by a greater suppressing effect of vagotomy on insulin secretion in HG than in C rats. The stimulatory effect of the parasympathetic nerve on insulin release is mediated by acetylcholine. It is now recognized that neural signals from the vagus to the $\beta$ cell participate in the cephalic phase of insulin secretion (14). Interestingly, several lines of evidence suggest that acetylcholine contributes to the pancreatic $\beta$ cell sensitization to glucose. Zawalich et al. (13) showed that when pancreatic islets were previously exposed to cholinergic agonists such as carbachol, the subsequent insulin secretory response to a submaximal glucose concentration ( $7.5 \mathrm{mM})$ was significantly increased. Moreover, acetylcholine stimulates phosphoinositide turnover (41). An important role in the induction of glucose memory in pancreatic islets has been ascribed to phosphoinositide metabolism (42), especially via the generation of diacylglycerol as well as the activation of the $\mathrm{Ca}^{2+}$-dependent protein kinase (43). Our findings match these data and support the concept of a crucial contribution of vagal stimulation to the control of insulin secretion, at least in part, by means of the sensitization of islets to glucose.

Sympathetic stimulation suppresses insulin secretion mainly through the release of norepinephrine by postsynaptic fibers (12). The inhibitory effect of norepinephrine is exerted by the activation of postsynaptic $\alpha_{2}$ adrenoreceptors (44). Recently it has been proposed that in the pancreatic $\beta$ cell the $\alpha_{2 \mathrm{~A}}$ subtype rather than the $\alpha_{2 \mathrm{~B}}$ subtype is specifically involved in the inhibition of insulin release (45). Therefore, to verify whether the decreased sympathetic activity consecutive to hyperglycemia could influence insulin secretion, we used an adrenoreceptor agonist specific for the $\alpha_{2 \mathrm{~A}}$ subtype, oxymetazoline (45). Clearly, the inhibitory effect of oxymetazoline in HG rats, which was much more marked than in controls, argues for the involvement of low sympathetic tone in the high $\beta$ cell responsiveness to glucose in these rats.

In conclusion, prolonged hyperglycemia in rats results in an overall increase of parasympathetic and a decrease in sympathetic activities. As a consequence, these alterations contribute to the sensitization of pancreatic islets to glucose. Taken together, these data support the view of participation of the autonomic nervous system in the in vivo $\beta$ cell memory to glucose and suggest that a loop links plasma glucose concentration, autonomic nervous system activity, and insulin secretion.

\section{Acknowledgments}

We are indebted to Nathalie Cholet and Benoit Poulin for their very expert technical assistance.

This work was supported by a grant from the Institut National de la Santé et de la Recherche Médicale (INSERM. CRE n920306).

\section{References}

1. Cerasi, E. 1975. Potentiation of insulin release by glucose in man. I. Quantitative analysis of the enhancement of glucose induced insulin secretion by pretreatment with glucose in normal subjects. Acta Endocrinol. 79:483-488.

2. Efendic, S., E. Cerasi, R. Luft, and G. Gladnikoff. 1976. Potentiation of glucose induced insulin release by glucose in the isolated pancreas of fed and fasted rats. Diabetes. 24:949-954.

3. Grill, V., U. Adamson, and E. Cerasi. 1978. Immediate and time-dependent effects of glucose on insulin release from rat pancreatic tissue. Evidence for different mechanisms of action. J. Clin. Invest. 61:1034-1043.
4. Grodsky, G. M. 1972. A threshold distribution hypothesis for packet storage of insulin and its mathematical modeling. J. Clin. Invest. 51:2047-2059.

5. Ward, W., J. Halter, J. Beard, and D. J. Porte. 1984. Adaptation of $\beta$ and $\alpha$ cell function during prolonged glucose infusion in man. Am. J. Physiol. 246:E405E411.

6. Kahn, S., R. Bergman, M. Schwartz, G. J. Taborsky, and D. J. Porte. 1992 Short-term hyperglycemia and hyperinsulinemia improve insulin action but do not alter glucose action in normal humans. Am. J. Physiol. 262:E518-E523.

7. Laury, M. C., F. Takao, D. Bailbé, L. Pénicaud, B. Portha, L. Picon and A. Ktorza. 1991. Differential effects of prolonged hyperglycemia on insulin secretion in vivo and in vitro in the rat. Endocrinology. 128:2526-2533.

8. Grill, V., and Y. Sako. 1990. Beta cell insensitivity to glucose: role of chronic hyperglycemia versus other factors. In Frontiers in Diabetes Research Lessons from Animal Diabetes, Volume III. E. Shafrir and A. E. Renold, editors. J. Libbey, France. 342-344.

9. Marynissen, G., V. Leclercq-Meyer, A. Sener, and W. Malaisse. 1990 Perturbation of pancreatic islet function in glucose-infused rats. Metabol. Clin. Exp. 39:87-95.

10. Leahy, J. L., H. E. Cooper, D. A. Deal, and G. C. Weir. 1986. Chronic hyperglycemia is associated with impaired glucose influence on insulin secretion. A study in normal rats using chronic in vivo glucose infusions. J. Clin. Invest. 77:908-915.

11. Leahy, J. L., S. Bonner-Weir, and G. C. Weir. 1988. Minimal chronic hyperglycemia is a critical determinant of impaired insulin secretion after an incomplete pancreatectomy. J. Clin. Invest. 81:1407-1414.

12. Ahren, B., G. J. Taborsky, and D. J. Porte. 1986. Neuropeptidergic versus cholinergic and adrenergic regulation of islet hormone secretion. Diabetologia. 29:827-836

13. Zawalich, W., K. Zawalich, and H. Rasmussen. 1989. Cholinergic agonists prime the $\beta$-cell to glucose stimulation. Endocrinology. 125:2400-2406.

14. Jeanrenaud, B. S., S. Halimi, and G. Van de Werve. 1985. Neuro-endocrine disorders seen as a triggers of the triad: obesity-insulin resistance-abnormal glucose tolerance. Diabetes Metab. Rev. 1:261-291.

15. Atef, N., A. Ktorza, L. Picon, and L. Pénicaud. 1992. Increased islet blood flow in obese rats: role of the autonomic nervous system. Am. J. Physiol. 262:E736-E740.

16. Ktorza, A., J. Girard, M. F. Kinebanyan, and L. Picon. 1981. Hyperglycaemia induced by glucose infusion in the unrestrained pregnant rat during the last three days of gestation: metabolic and hormonal changes in the mother and the fetuses. Diabetologia. 21:569-574.

17. Thibault, C., C. Guettet, M. C. Laury, J. M. N'Guyen, M. A. Tormo, D. Bailbé, B. Portha, L. Pénicaud, and A. Ktorza. 1993. In vivo and in vitro increased pancreatic $\beta$-cell sensitivity to glucose in normal rats submitted to a 48-h hyperglycaemic period. Diabetologia. 36:589-595.

18. Brelje, J. C., and R. L. Sorenson. 1988. Nutrient and hormonal regulation of the threshold of glucose-stimulated insulin secretion in isolated rat pancreases. Endocrinology. 123:1582-1590.

19. Timmers, K. I., A. M. Powell, N. R. Voyles, D. Solomon, S. D. Wilkins, S. Bhathena, and L. Recant. 1990. Multiple alterations in insulin responses to glucose in islets from $48 \mathrm{~h}$ glucose-infused non diabetic rats. Diabetes. 39:14361444.

20. Purello, F., M. Vetri, C. Gatta, D. Gullo, and R. Vigneri. 1989. Effects of high glucose on insulin secretion by isolated islets and purified rat $\beta$-cells and possible role of glycosylation. Diabetes. 38:1417-1422.

21. Andersson, A. 1974. Long-term effects of glucose on insulin release and glucose oxidation by mouse pancreatic islets. Biochem. J. 140:377-382.

22. Purello, F., M. Buscema, A. M. Rabuazzo, V. Caltabiano, F. Forte, C. Vinci, M. Vetri, and R. Vigneri. 1993. Glucose modulates glucose transporter affinity, glucokinase activity, and secretory response in rat pancreatic $\beta$-cell. Diabetes. 42:199-205.

23. Niijima, A. 1975. The effect of glucose on the activity of the adrenal nerve and pancreatic branch of the vagus nerve in the rabbit. Neurosci. Lett. $1: 159-162$.

24. Niijima, A. 1982. Glucose-sensitive afferent nerve fibres in the hepatic branch of the vagus nerve in the guinea pig. J. Physiol. (Camb.). 332:315-323.

25. Niijima, A. 1985. Blood glucose levels modulate efferent activity in the vagal supply to the rat liver. J. Physiol. (Camb.). 364:105-112.

26. Young, J. B., J. W. Rowe, J. A. Pallotta, D. Sparrow, and L. Landsberg. 1980. Enhanced plasma norepinephrine response to upright posture and oral glucose administration in elderly human subjects. Metab. Clin. Exp. 29:532-539.

27. Young, J. B., and L. Landsberg. 1977. Stimulation of the sympathetic nervous system during glucose feeding. Nature (Lond.). 269:615-617.

28. Walgren, M., J. Young, and L. Landsberg. 1987. The effects of various carbohydrates on sympathetic nervous activity in heart and inter-scapular brown adipose tissue (IBAT) of the rat. Metab. Clin. Exp. 36:585.

29. Young, J. B., and L. Landsberg. 1977. Suppression of sympathetic nervous system during fasting. Science (Wash. DC). 196:1473-1475.

30. Young, J. B., and L. Landsberg. 1979. Sympathoadrenal activity in fasting 
pregnant rats. Dissociation of adrenal medullary and sympathetic nervous system responses. J. Clin. Invest. 64:109-116.

31. Landsberg, L., L. Greff, S. Gunn, and J. Young. 1980. Adrenergic mechanisms in the metabolic adaptation to fasting and feeding: effect of phlorizin on diet-induced changes in sympathoadrenal activity in the rat. Metab. Clin. Exp. 29(Suppl 1):1128-1137.

32. Young, J., D. Einhorn, and L. Landsberg. 1983. Decreased sympathetic (SNS) activity in inter-scapular brown adipose tissue (IBAT) of streptozotocintreated rats. Diabetes. 32(suppl):26A(103).

33. Berne, C., and J. Fagius. 1986. Skin nerve sympathetic activity during insulin-induced hypoglycemia. Diabetologia. 29:855-860.

34. Berne, C., J. Fagius, T. Pollare, and P. Hjemdahl. 1992. The sympathetic response to euglycemic hyperinsulinaemia. Evidence from microelectrode nerve recordings in healthy subjects. Diabetologia. 35:873-879.

35. Vollenweider, P., L. Tappy, D. Randin, P. Schneiter, E. Jéquier, P. Nicod, and U. Scherrer. 1993. Differential effects of hyperinsulinemia and carbohydrate metabolism on sympathetic nerve activity and muscle blood flow in humans. $J$. Clin. Invest. 92:147-154.

36. Niijima, A. 1975. An electrophysiological study on the regulatory mechanism of blood sugar level in the rabbit. Brain Res. 87:195-199.

37. Niijima, A. 1977. Nervous regulatory mechanism of blood glucose levels. In Food Intake and Chemical Senses. Y. Katsuki, M. Sato, S. F. Takagi, and Y. Oomura, editors. University of Tokyo Press, Tokyo. 413-426.
38. Wilke, R., D. Riley, P. Lelkes, and C. Hillard. 1993. Decreased catecholamine secretion from the adrenal medullae of chronically diabetic BB-Wistar rats. Diabetes. 42:862-868.

39. Cryer, P., and J. Gerich. 1985. Glucose counterregulation, hypoglycemia, and intensive insulin therapy in diabetes mellitus. N. Engl. J. Med. 313:232-241.

40. Towler, D., C. Havlin, S. Craft, and P. Cryer. 1993. Mechanism of awareness of hypoglycemia. Perception of neurogenic (predominantly cholinergic) rather than neuroglycopenic symptoms. Diabetes. 42:1791-1798.

41. Abdel-latif, A. 1986. Calcium-mobilizing receptors, polyphosphoinositides, and the generation of second messengers. Pharmacol. Rev. 38:227-272.

42. Zawalich, W., V. Diaz, and K. Zawalich. 1988. Role of phosphoinositide metabolism in induction of memory in isolated perfused rat islets. Am. J. Physiol. E609-E616.

43. Niki, I., T. Tamagawa, H. Niki, A. Niki, T. Koide, and N. Sakamoto. 1988. Possible involvement of diacylglycerol-activated $\mathrm{Ca}^{2+}$-dependent protein kinase in glucose memory of the rat pancreatic B-cell. Acta Endocrinol. 118:204208.

44. Angel, I., R. Niddam, and S. Langer. 1990. Involvement of $\alpha_{2}$-adrenergic receptor subtypes in hyperglycemia. J. Pharmacol. Exp. Ther. 254:877-882.

45. Niddam, R., I. Angel, S. Bidet, and S. Langer. 1990. Pharmacological characterization of alpha-2 adrenergic receptor subtype involved in the release of insulin from isolated rat pancreatic islets. J. Pharmacol. Exp. Ther. 254:883887. 